\title{
Genetic variation and demographic contraction of the remnant populations of Mexican Caribbean pine (Pinus caribaea var. hondurensis: Pinaceae)
}

\author{
Patricia Delgado • Daniel Piñero • Virginia Rebolledo • \\ Lev Jardón • Francisco Chi
}

Received: 4 December 2009 /Accepted: 28 April 2010/Published online: 15 February 2011

(C) INRA and Springer Science+Business Media B.V. 2011

\begin{abstract}
- Introduction The recognition of endangered species takes into account geographic isolation and small size of populations, as is the case of two populations of Pinus caribaea var. hondurensis distributed in México.

- Materials and methods This study evaluates the genetic variation within and among Mexican populations of $P$. caribaea var. hondurensis to make inferences on the historical dynamics of the populations by screening a total of 69 trees with six nuclear microsatellites.

- Results The results indicate intermediate levels of genetic variation in both populations $\left(H_{\mathrm{E}}=0.465\right)$. The level of inbreeding was significant for both populations (Caobas $F_{\text {IS }}=$ 0.097; Pioneros $F_{\mathrm{IS}}=0.163$ ), but the effective population size was higher in the Pioneros population $\left(N_{\mathrm{e}}=868\right)$ compared to Caobas $\left(N_{\mathrm{e}}=402\right)$. Average genetic differentiation was low $\left(R_{\mathrm{ST}}=0.033\right)$ and historical migration rate was relatively high $(M=13.2)$.
\end{abstract}

Handling Editor: Luc Pâques

\section{P. Delgado $(\square)$}

Facultad de Agrobiología "Presidente Juárez",

Universidad Michoacana de San Nicolás de Hidalgo,

Av. Revolución esquina con,

Berlín S/N,

CP 60091, Uruapan, Michoacán, México

e-mail: dvalerio@umich.mx

D. Piñero $\cdot$ L. Jardón

Instituto de Ecología,

Universidad Nacional Autónoma de México,

Apartado Postal 70-275,

México, Distrito Federal 04510, México

V. Rebolledo $\cdot$ F. Chi

Centro de Investigación Científica de Yucatán,

A. C, Calle 43, Número 130, Colonia Chuburná de Hidalgo,

97200, Mérida, Yucatán, México
- Discussion These results, together with the analysis of bottlenecks, provide us evidence of historical events of contraction of the population size, which probably occurred between 8,100 and 35,000 years ago. We propose conservation strategies for the emergent recovery of these remaining native forest patches.

Keywords Caribbean pine - Nuclear microsatellites . Population genetics $\cdot$ Conservation $\cdot$ Mexico

\section{Introduction}

The probability of extinction of a species depends on its intrinsic characteristics and factors that alter the environment where it grows (Lande 1993). Generally, the recognition of species as endangered accounts for both demographic and genetic processes, which are related to geographic isolation and small population sizes (Lande 1993). Geographic isolation can initiate population divergence through mutation and genetic drift (Karhu et al. 2005). Fluctuations in population size can decrease the effective population size and may result in the loss of genetic variation, as well as processes of inbreeding with the resulting local or global population extinction (Shaffer 1981; Boyce 1992). Therefore, small populations are more susceptible to extinction than large populations and extrinsic or environmental factors increase that risk.

Genetic models have been used to infer demographic processes of species, such as colonization, expansion, growth rates, bottlenecks, and founder effects (Maruyama and Fuerst 1985; Cornuet and Luikart 1996). Several studies have used this type of approach in conifers. Karhu et al. (2005) with nuclear microsatellites inferred the presence of expansion events in the populations of Pinus 
radiata D Don. on the islands of Guadalupe and Cedros in Mexico. Jaramillo-Correa et al. (2006) used chloroplast microsatellites to infer demographic bottlenecks in some populations of Picea chihuahuana Mart. distributed in the Sierra Madre Occidental of Mexico. Al-Rabab'ah and Williams (2004) found, with nuclear microsatellites, that the loss of natural populations of Pinus taeda L. in central Texas (USA), is due to the drastic size reductions that occurred during and after the Pleistocene. Ledig et al. (1999) found reduced allozyme variation for the only known population of Pinus maximartinezii Rzed., an endemic to Mexico, suggesting a drastic reduction in the population size by recent bottleneck events. These works are representative of species with fragmented and restricted distributions and have demonstrated the utility of the genetic approach for conservation.

Pinus caribaea var. hondurensis (Sénécl) Barr. et Golf. (Caribbean pine) is a tropical species with the southernmost and lowest elevation distribution of American pines (from 1 to $1000 \mathrm{~m}$; Farjon and Styles 1997). It is represented by some large and continuous populations (Belize, Nicaragua, Honduras) and several that are restricted and fragmented (Belize, Guatemala, and Mexico; Dvorak et al. 2005). Only a single population was known from Mexico formerly, occurring in the Ejido of Caobas in the locality known as "Jaguactal" in the state of Quintana Roo. According to different authors, this population consists of 150 (Macario et al. 1998; this study) to 1,000 (Dvorak et al. 2005) reproductive trees and is considered endangered (NOM059-2001). In this study, we report a new population located on the southern boundary of the states of Campeche and Quintana Roo. This population is extremely small, with only 14 reproductive trees. These two populations represent the northernmost distribution reported for the species, and like other populations in Belize, they are found in isolated areas within forest savanna called "swamps". These habitats are characterized by periods of drought and extreme humidity and very acidic, impermeable soils which floods in the rainy season (June to October).

The current geographic distribution, as well as the ecological conditions in which the Mexican populations occur, suggest the hypothesis that both populations represent remnants of a wider distribution of the species, which diminished due to climate changes, specifically extreme droughts, floods, and the presence of hurricanes.

Recently, Dvorak et al. (2005) used a predictive climatic model to propose that $P$. caribaea var. hondurensis had a larger distribution in the past $(7,000-8,000$ years BC), and today, it should occur along the east coast of Yucatan, as far north as Puerto Juarez, Quintana Roo. In addition, Furman (1997) using RAPDs from several populations, found that two localities of Belize and the Caobas locality in Mexico are very similar, but very different genetically from populations in Honduras and Nicaragua, suggesting that they might be satellite populations derived from a core population.

In this sense, the study of the Mexican population of P. caribaea var. hondurensis is of great relevance for both evolutionary ecology and conservation biology because (1) as the northernmost populations of the species, it could represent evidence that this region was an important past route of dispersal among America (from the northeast of the Yucatan Peninsula) and the Caribbean islands, (2) these populations could contain unique genetic variants which could be of great adaptive value, and (3) their extremely small population size requires the generation of basic information that allows specific strategies for restoration and conservation. Currently, no work exists that includes genetic material from these two populations (Furman (1997) only used material from one individual of the locality of Caobas), nor any demographic study that could help us understand their population dynamics. In the present study, we analyze molecular data (nuclear microsatellites: nSSR) to determine the dynamics of local extinction of these populations as well as to infer demographic events that have influenced their evolutionary history. We selected nuclear microsatellites as genetic markers because they are highly polymorphic, codominant, and compatible with population genetic theory (Petit et al. 2005). The goals of this study were to: (1) estimate levels of variation and genetic structure, inbreeding and the effective size of the Mexican population of P. caribaea var. hondurensis, (2) test the hypothesis that a bottleneck diminished the levels of genetic variation and population differentiation, and (3) generate specific strategies for conservation of these remnant native forest patches.

\section{Materials and methods}

\subsection{Study area}

The two Mexican populations of $P$. caribaea var. hondurensis are distributed in the southern states of Quintana Roo and Campeche. The population of Caobas (CAOB) is located in the area known as the "Jaguactal" in the Ejido of Caobas, Municipality of Othon P. Blanco, Quintana Roo (between $18^{\circ} 15^{\prime} 12.5^{\prime \prime} \mathrm{N}$ and $88^{\circ} 57^{\prime} 45.6^{\prime \prime} \mathrm{W}$; Fig. 1). The population of Pioneers (PION) is in the Ejido Pioneros del Río Nuevo Centro Poblacional within the natural reserve of Calakmul, on the southern limit of the states of Campeche and Quintana Roo (between $17^{\circ} 53^{\prime} 05^{\prime \prime} \mathrm{N}$ and $89^{\circ} 10^{\prime} 44^{\prime \prime} \mathrm{W}$ ). The CAOB population is represented by 150 to 200 trees with most individuals $(>60 \%)$ between 50 and 80 years and fewer seedlings and saplings $(<15 \%)$, whereas the PION population is represented by only 14 mature trees older than 80 years, and no regeneration (Rebolledo et al. unpublished 
Fig. 1 Geographic location of the Mexican populations of $P$. caribaea var. hondurensis. Gray color represents the natural distribution of the variety

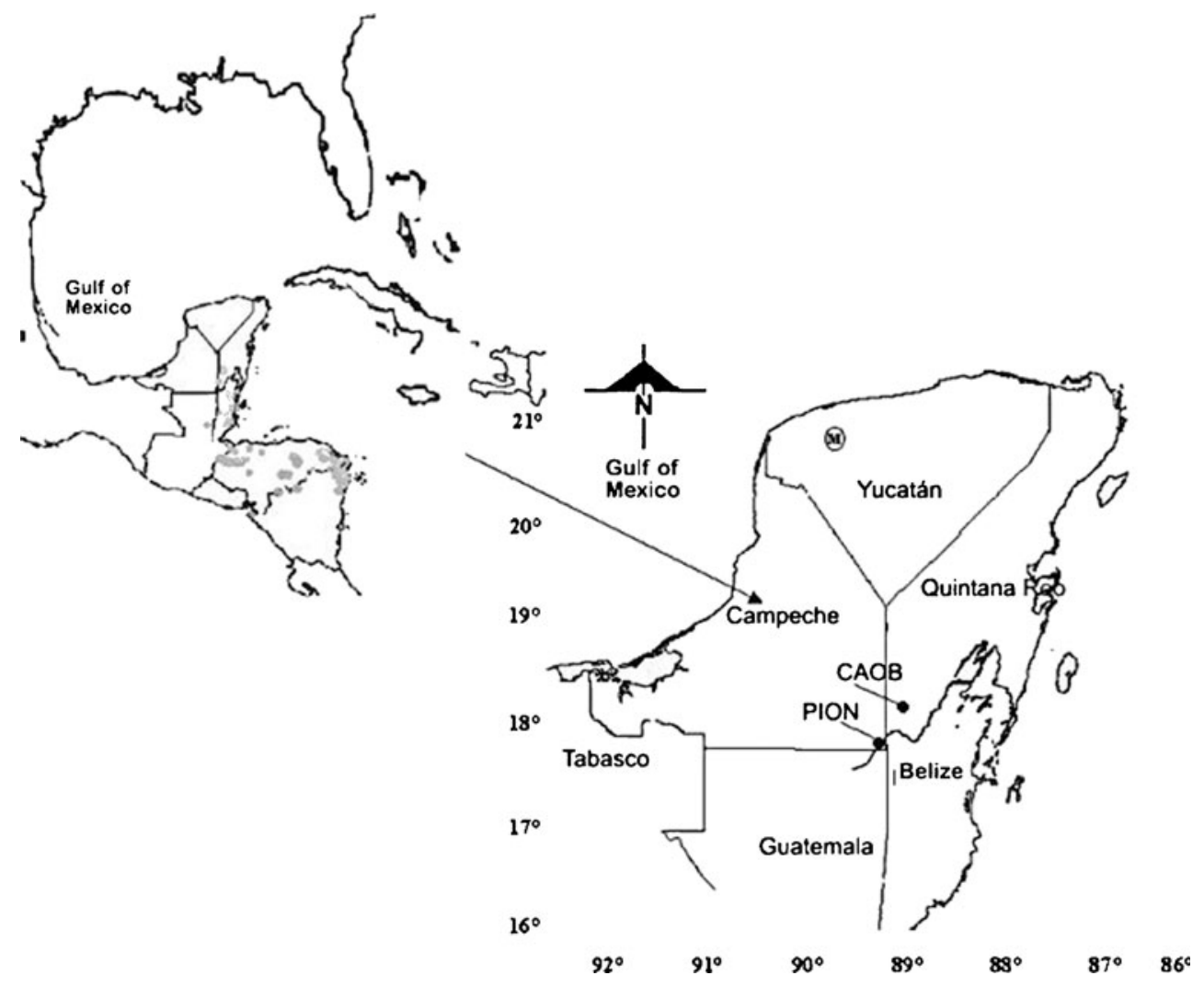

data). This species grows in Gleysols characterized by possessing a great quantity of clay with a strong plasticity and adhesiveness when humid, while when dry, it shrinks and develops cracks and fissures (Macario et al. 1998). The topography is relatively flat and uniform; the altitudes of the CAOB and of the PION population are 130 and $68 \mathrm{msnm}$, respectively. The vegetation is characterized by representative species of the forest savanna (Curatella americana L, Crescentia cujente L, and Scleria sp.) and temporally flooded lowland forest (Haematoxylum campechianum L, Clusia chanekiana Lundell, Mimosa bahamensis Benth, and Erythroxylum confusum Britton). The climate is tropical in both populations with an average annual rainfall of $1,300 \mathrm{~mm}$ and an average temperature of $26^{\circ} \mathrm{C}$ (Macario et al. 1998).

\subsection{Collection of material}

In February 2006, ecological data and biological material were obtained. For the CAOB population, a census of its entire distribution area was conducted $(\sim 4 \mathrm{ha})$, and three transects were placed in the area with the greatest density of individuals. Along these transects, one small branch per tree was collected from a total of 60 individuals. For the PION population, samples were collected from all 14 trees found in an area of about 2 ha. The samples were labeled and stored at $-70^{\circ} \mathrm{C}$ until DNA extraction.

\subsection{Microsatellites}

Genomic DNA was extracted using a Miniprep CTAB method (Vázquez-Lobo 2006). Eighteen primers were tested; 14 derived from P. taeda (Elsik et al. 2000) and four from Pinus resinosa (Boys et al. 2005), of which six polymorphic microsatellites with good resolution were selected (Table 1). The amplification reactions and PCR conditions were performed using the methodology developed for $P$. taeda (Elsik et al. 2000). The fragments were separated on polyacrylamide gels $6 \%$ (7 M of urea) and run at $55 \mathrm{~W}$ for 1.5 to $3.5 \mathrm{~h}$, depending on the size of the fragments. The polymorphisms were displayed with the silver nitrate staining method (Echt et al. 1996), and fragment size was determined visually using a 10-bp reference marker.

According to the molecular analyses of Shepherd et al. (2002), five of the six microsatellites used in this study did not show null alleles. However, we estimated null allele frequencies for each locus with Micro-Checker 2.2.3 (Van Oosterhout et al. 2004). The results indicate a relatively low proportion of null alleles for $\mathrm{CAOB}$ population in two loci (PtTX2146, proportion 0.166; PRE13, proportion 0.132). To remove these null alleles, we performed this analysis again excluding five individuals that the Micro-Cheker program suggested. Based on this result, the analysis of genetic variation of $\mathrm{CAOB}$ population was realized on a total of 55 individuals that did not present null alleles. 
Table 1 Allele frequencies obtained for Mexican populations of $P$. caribaea var. hondurensis

\begin{tabular}{|c|c|c|c|}
\hline \multirow[b]{2}{*}{ Locus } & \multicolumn{3}{|c|}{ Population } \\
\hline & Alleles & Caobas (CAOB) & Pioneros (PION) \\
\hline \multirow[t]{3}{*}{ PtTX2123 } & 201 & 0.916 & 0.964 \\
\hline & 191 & 0.027 & 0.036 \\
\hline & 198 & 0.063 & 0 \\
\hline \multirow[t]{4}{*}{ PtTX3025 } & 267 & 0.009 & 0 \\
\hline & 268 & 0.718 & 0.785 \\
\hline & 252 & 0.236 & 0.178 \\
\hline & 272 & 0.036 & 0.036 \\
\hline \multirow[t]{4}{*}{ PtTX3013 } & 142 & 0.109 & 0 \\
\hline & 134 & 0.872 & 0.607 \\
\hline & 125 & 0.009 & $0.714 \mathrm{~s}$ \\
\hline & 145 & 0.009 & 0.321 \\
\hline \multirow[t]{3}{*}{ PtTX2146 } & 181 & 0.566 & 0.679 \\
\hline & 177 & 0.400 & 0.321 \\
\hline & 165 & 0.033 & 0 \\
\hline \multirow[t]{4}{*}{ PtTX3020 } & 187 & 0.259 & 0.214 \\
\hline & 181 & 0.241 & 0.214 \\
\hline & 167 & 0.037 & 0.071 \\
\hline & 195 & 0.463 & 0.500 \\
\hline \multirow[t]{6}{*}{ PRE13 } & 240 & 0.239 & 0.500 \\
\hline & 244 & 0.185 & 0.231 \\
\hline & 252 & 0.271 & 0.269 \\
\hline & 230 & 0.087 & 0 \\
\hline & 270 & 0.065 & 0 \\
\hline & 255 & 0.152 & 0 \\
\hline \multicolumn{2}{|c|}{ No. of alleles/locus } & 4.000 & 2.833 \\
\hline
\end{tabular}

Genetic diversity was determined by observed $\left(H_{\mathrm{O}}\right)$ and expected $\left(H_{\mathrm{E}}\right)$ heterozygosity, the repeat size range of the alleles, the number of alleles per locus per population, and the mean number of alleles per locus. The genetic structure $\left(R_{\mathrm{ST}}\right)$ was obtained according to the stepwise mutation model (SMM; Kimura and Otha 1978) and inbreeding coefficient $\left(F_{\text {IS }}\right)$ according to Wright (1965). These estimates were made with the program Arlequin ver. 3.0 (Excoffier et al. 2005). The effective population size $\left(N_{\mathrm{e}}\right)$ and the effective migration rates $\left(M_{\mathrm{R}}=N_{\mathrm{e}} m\right)$ were estimated with a simulated annealing procedure of maximum likelihood assuming a mutation rate $(\mu)$ of $10^{-3}$ per generation (Boys et al. 2005), using the program Migrate ver. 3.0 (Beerli 2008). The $N_{\mathrm{e}}$ was calculated as $\Theta / 4 \times 10^{-3}$ (Boys et al. 2005), and $M_{\mathrm{R}}$ as $m / \mu$ (Beerli 2006). To infer the consequences of demographic processes on the levels of genetic diversity of populations, we tested the "bottleneck" hypothesis with two methods: the first was "heterozygosity excess", which assumes that when a population experiences a recent reduction of their effective population size, it tends to exhibit a reduction in the number of alleles and in heterozygosity (Cornuet and Luikart 1996). The heterozygosity $\left(H_{\mathrm{E}}\right)$, theoretically is higher than expected heterozygosity $\left(H_{\mathrm{Eq}}\right)$ at mutation-drift equilibrium calculated from allele number (Cornuet and Luikart 1996; Luikart et al. 1998). The second method was the graphic representation of the "mode shift indicator" (Luikart et al. 1998). The reduction or loss of classes of allele frequencies "shifts" can be detected by comparing the distribution of alleles in a population to the distribution that would be expected at mutation-drift equilibrium (Maruyama and Fuerst 1985; Luikart et al. 1998). Both analyses assume a stepwise mutation model and were performed using Bottleneck 1.2.02 software (Piry et al. 1999).

\section{Results}

\subsection{Genetic variation}

For the six selected loci, the repeat size of the alleles ranged from 2 to $20 \mathrm{bp}$ showing higher frequency alleles with repeat sizes from 2 to $6 \mathrm{bp}$. A total of 24 alleles were found in the CAOB population, and 17 alleles in the PION population, with an average of 4.00 and 2.83 alleles per locus, respectively. The most frequent alleles for both populations were 201 (PtTX2123), 168 (PtTX3025), 134 (PtTX3013), 181 (PtTX2146), 195 (PtTX3020), and 240 (PRE13) (Table 1). The average expected and observed heterozygosity of CAOB population $\left(H_{\mathrm{E}}=0.471, H_{\mathrm{O}}=0.459\right)$ were slightly higher than PION $\left(H_{\mathrm{E}}=0.459, H_{\mathrm{O}}=0.386\right)$. Both populations had a deficit of heterozygotes compared to random mating expectation, and thus a significant coefficient value $\left(\mathrm{CAOB} F_{\mathrm{IS}}=0.097, P=0.045\right.$; PION $F_{\mathrm{IS}}=0.163, P=$ 0.003; Table 2). The estimated effective size $\left(N_{\mathrm{e}}\right)$ was higher in the population of PION $\left(N_{\mathrm{e}}=868\right)$ than in CAOB $\left(N_{\mathrm{e}}=402\right)$.

The genetic structure among populations was low but significant $\left(R_{\mathrm{ST}}=0.033, P=0.037\right)$, and the average gene flow was relatively high $(M=13.2)$. Gene flow from PION to CAOB $(M=16.1)$ was slightly higher than from CAOB to PION $(M=10.3)$, suggesting historical asymmetric gene flow.

\subsection{Demographic history}

For three loci (PtTX2123, PtTX 3025, and PtTX3013), the bottleneck analysis based on the "heterozygosity excess" model had heterozygosity values $\left(H_{\mathrm{E}}\right)$ that were lower than expected under mutation-drift equilibrium $\left(H_{\mathrm{Eq}}\right)$ for each population and for the total gene pool (Table 3). This suggests a significant loss of genetic diversity due to fragmentation and decrease in population size.

The mode shift analysis revealed more than one allele class, with medium and high frequencies ( 0.3 to 0.7$)$, as well 
Table 2 Parameters of genetic diversity estimated for Mexican populations of $P$. caribaea var. hondurensis

\begin{tabular}{llllll}
\hline Population & $N$ & $A$ & $H_{\mathrm{O}}$ & $H_{\mathrm{E}}$ & $F_{\mathrm{IS}}$ \\
\hline CAOB & 55 & 24 & $0.459(0.226)$ & $0.471(0.247)$ & $0.097^{\mathrm{a}}$ \\
PION & 14 & 17 & $0.386(0.207)$ & $0.459(0.222)$ & 1.60 \\
Average & 37 & 20.5 & $0.422(0.216)$ & $0.465(0.235)$ & 3.27 \\
\hline
\end{tabular}

Values in parentheses are standard deviation

$N$ size, $A$ allele number, $H_{\mathrm{O}}$ and $H_{\mathrm{E}}$ observed and expected heterozygosity, $F_{\mathrm{IS}}$ fixation index, $\Theta$ genetic diversity parameter (4N $u$ ), $N_{\mathrm{e}}$ population effective size

${ }^{\text {a }}$ Significant deviations from $F_{\text {IS }}=0$ at 0.05 probability

as a the highest frequency (0.8) of two and three class of alleles for PION and CAOB, respectively. The CAOB population contains the largest number of allele classes with low frequencies, lower than 0.1. Also, both populations have two gaps with loss of classes of allelic frequencies (gaps 4 and 7 for $\mathrm{CAOB}$ and 8 and 9 for PION; Fig. 2). These results corroborate the existence of events of population size contraction with the consequent loss of allelic variants.

\section{Discussion}

\subsection{Genetic variation and demographic history}

Our results show significant levels of genetic variation in CAOB and PION, although they are lower than those obtained with nSSR for other pine species (e.g., $P$. radiata $H_{\mathrm{O}}=0.625$, (Smith and Devey 1994); $H \mathrm{o}=0.670$, (Karhu et al. 2005); Pinus strobus $H_{O}=0.515$, (Echt et al. 1996), $P$. taeda $H_{O}=0.559$, (Elsik et al. 2000); P. caribaea var. hondurensis $H_{\mathrm{O}}=0.490$, (Shepherd et al. 2002); $H_{\mathrm{O}}=0.527$, (Rebolledo et al., unpublished data), and Pinus elliottii var. elliottii $H_{\mathrm{O}}=0.500$, (Shepherd et al. 2002)). For the study of Shepherd et al. (2002), the estimation was based on a sample size of five individuals and should be taken with care. However, the study by Rebolledo et al. (unpublished data) was based on an average of 20 individuals from seven populations distributed in Belize and Honduras, and with four of the nSSR used in this study. Therefore, the genetic diversity of the two Mexican populations is still lower than that obtained in other populations of $P$. caribaea var. hondurensis and most pine species analyzed with nSSR.

An exceptional case is $P$. resinosa, a species of wide but fragmented distribution, for which Boys et al. (2005) reported an average of $H_{\mathrm{o}}=0.185$, below the one obtained in this study. They consider that this low value may be due to recent colonization event. At the population level, $H_{\mathrm{E}}$ from $\mathrm{CAOB}$ and PION were higher than $H_{\mathrm{O}}$, and $F_{\mathrm{IS}}$ was significant $\left(\mathrm{CAOB} F_{\text {IS }}=0.097\right.$; PION $F_{\text {IS }}=0.163$ ), which suggest a higher average rate of inbreeding. In contrast, the

Table 3 Results of the bottleneck analyses performed with the heterozygosity excess model in the Mexican populations of $P$. caribaea var. hondurensis

\begin{tabular}{|c|c|c|c|c|c|c|c|}
\hline Population & Locus & $K_{\mathrm{n}}$ & $H_{\mathrm{E}}$ & $H_{\mathrm{Eq}}$ & SD & $\mathrm{DH} / \mathrm{sd}$ & $P$ \\
\hline \multirow[t]{6}{*}{ CAOB } & ptTX2123 & 3 & 0.172 & 0.471 & 0.139 & -2.151 & $0.054 *$ \\
\hline & ptTX3025 & 4 & 0.435 & 0.603 & 0.107 & -1.578 & $0.050^{*}$ \\
\hline & ptTX3013 & 4 & 0.230 & 0.608 & 0.101 & -3.738 & $0.004^{*}$ \\
\hline & ptTX2146 & 3 & 0.530 & 0.494 & 0.130 & 0.277 & 0.471 \\
\hline & ptTX3020 & 4 & 0.672 & 0.608 & 0.103 & 0.621 & 0.301 \\
\hline & PRE13 & 6 & 0.818 & 0.749 & 0.065 & 1.059 & 0.076 \\
\hline \multirow[t]{6}{*}{ PION } & ptTX2123 & 2 & 0.072 & 0.342 & 0.146 & -1.901 & $0.0000^{*}$ \\
\hline & ptTX3025 & 3 & 0.362 & 0.565 & 0.108 & -1.809 & $0.0430^{*}$ \\
\hline & ptTX3013 & 3 & 0.542 & 0.570 & 0.109 & -0.081 & 0.3930 \\
\hline & ptTX2146 & 2 & 0.452 & 0.345 & 0.147 & 0.796 & 0.3190 \\
\hline & ptTX3020 & 4 & 0.677 & 0.691 & 0.077 & 0.161 & 0.4860 \\
\hline & PRE13 & 3 & 0.649 & 0.573 & 0.108 & 1.143 & 0.0750 \\
\hline
\end{tabular}

$S M M$ Stepwise mutation model, $K_{\mathrm{n}}$ number of alleles per locus, $H_{\mathrm{E}}$ expected heterozygosity, $H_{\mathrm{Eq}}$ expected heterozygosity at mutation-drift equilibrium, $S D$ standard deviation of the mutation-drift equilibrium distribution of the heterozygosity, $H_{\mathrm{o}}-H_{\mathrm{e}} / s d$ standardized difference for each locus

${ }^{*} P=0.05$, probability of deficit for the expected heterozygosity $\left(H_{\mathrm{E}}\right)$ 


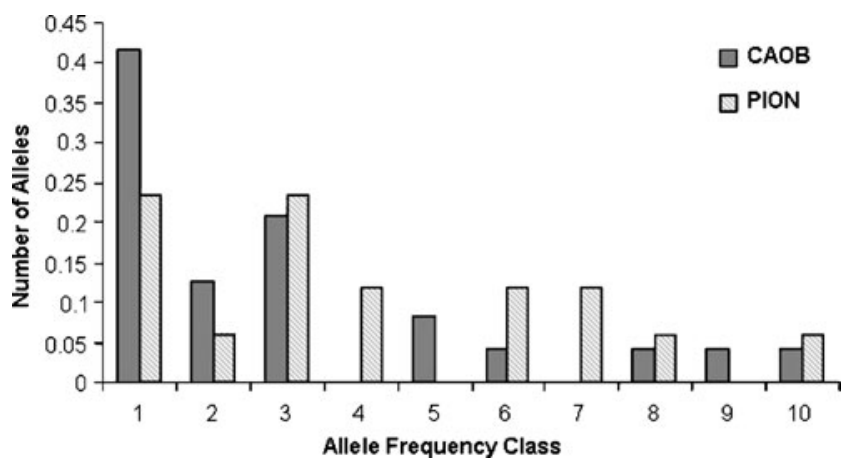

Fig. 2 Frequency distribution of allele classes for the Mexican populations of $P$. caribaea var. hondurensis obtained with the mode shift indicator

preliminary estimation of $F_{\text {IS }}$ obtained by Rebolledo et al. (unpublished data) was not significant $\left(F_{\mathrm{IS}}=0.035\right)$. This estimate is similar to that reported by Dvorak et al. (2005), with isozymes for populations of this variety from Belize and Guatemala $\left(F_{\mathrm{IS}}=0.011\right)$.

Another interesting result is the average number of alleles per locus, which was lower for both populations (CAOB, four alleles and PION, three alleles) than the average reported for other pine species, such as $P$. resinosa (nine alleles, (Boys et al. 2005)), P. radiata (six alleles, (Smith and Devey 1994); seven alleles, (Karhu et al. 2005)), Pinus oocarpa, Pinus patula, and Pinus tecunumanii (five alleles, (Dvorak et al. 2009)), and similar to other populations of P. caribaea var. hondurensis distributed in Belize and Honduras (four alleles, Rebolledo et al. unpublished data). In general, these results suggest that the Mexican populations of $P$. caribaea var. hondurensis are losing genetic diversity due possibly to genetic drift, and this is also reflected by an increase of inbreeding.

The decrease in effective population size $\left(N_{\mathrm{e}}\right)$ has been found to be the main cause for the loss of genetic diversity (Shaffer 1981; Karhu et al. 2005). For the CAOB population, which is represented by 150 to 200 individuals, the estimated $N_{\mathrm{e}}$ was 402 , less than the value obtained for PION (868), although the latter includes only 14 trees. Few studies have estimated the effective size with nSSR, but if we compare the $N_{\mathrm{e}}$ of the Mexican populations of this pine with the $N_{\mathrm{e}}$ obtained from $P$. resinosa $\left(N_{\mathrm{e}}\right.$ between 62 and 222; (Boys et al. 2005)), these values are relatively higher, which shows that the two populations have suffered a drastic reduction in census size and suggest that inbreeding has played an important role in the decline of genetic variation. In particular, for the PION population, the lower genetic diversity could be the result of a recent reduction in population size, without having a direct impact on the estimated $N_{\mathrm{e}}$. The latter, if we compare the $N_{\mathrm{e}}$ of PION with $\mathrm{CAOB}$ population, was higher than in $\mathrm{CAOB}$. An alternative explanation for these $N_{\mathrm{e}}$ values is that the population size of PION is larger than we observed.
These results combined with those obtained with the bottleneck analysis indicate that both populations have declined in size during their evolutionary history. $H_{\mathrm{E}}$ values for three of six loci were lower than expected under mutation-drift equilibrium for both populations, whereas the remaining three loci had opposite estimates, high values of $H_{\mathrm{E}}$ compared to $H_{\mathrm{Eq}}$ (e.g., PRE13 locus; Table 3). Such results are comparable to those obtained with other species of conifers (P. taeda (Al-Rabab'ah and Williams 2004); P. chihuahuana (Jaramillo-Correa et al. 2005)). In particular, in the study of P. taeda (Al-Rabab'ah and Williams 2004), which tested the hypothesis of bottlenecks in a population (Lost Pines) represented by 14 individuals, the $H_{\mathrm{E}}$ values obtained were lower than expected at drift-mutation equilibrium $\left(H_{\mathrm{Eq}}\right)$ for several loci, suggesting a reduction in allele diversity. The authors conclude that the Lost Pines population underwent events of ancestral bottlenecks (between 3,000 and 30,000 years ago). Our results are similar since $H_{\mathrm{E}}$ was lower than $H_{\mathrm{Eq}}$ for three loci, indicating a relatively ancient reduction of population size. The results obtained from the analysis of the classes of allelic frequencies corroborate this hypothesis, indicating a decline and loss of alleles in both populations, with a greater loss of alleles in the PION population. Small populations tend to lose rare alleles more rapidly than large populations (Maruyama and Fuerst 1985). Therefore, the PION population has suffered a great loss of alleles due to the effect of genetic drift, while the CAOB population has experienced a reduction in both census and effective sizes.

Dvorak et al. (2005) offered the hypothesis that $P$. caribaea var. hondurensis populations were distributed more continuously in the past. The results obtained in this work support two central aspects of this hypothesis: the first relates to the patterns of genetic structure found for pine species with geographically isolated or fragmented distributions, which are much higher than those obtained for species with wide distributions (Ledig 1998). Nevertheless, the value obtained in this study was low $\left(R_{\mathrm{ST}}=0.033\right)$, and relatively similar to the value obtained by Dvorak et al. (2005); $\left(F_{\mathrm{ST}}=\right.$ $0.023)$, suggesting that $P$. caribaea had a wider distribution in the past. This is also reflected in the high rates of ancestral gene flow obtained between Mexican populations $(M=13.1)$ regardless of the actual geographical fragmentation. The second aspect relates to the results obtained by Dvorak et al. (2005) with the predictive analysis of the distribution of the species. They conclude that $P$. caribaea var. hondurensis had a wider distribution in the Yucatan Peninsula in the past, with a demographic dynamics of contraction and expansion events generated by climate changes of drought and extreme floods that occurred during the last 10,000 years. We conclude that events of contraction that were detected in the Mexican populations could not have occurred in the recent past, or within $4 N_{\mathrm{e}}$ generations (less than 80 
generations; (Luikart et al. 1998)). To support this hypothesis, we can estimate the time during which these populations have decreased in size, based on a timeframe of $2 N_{\mathrm{e}}$ to $4 N_{\mathrm{e}}$ generations (Luikart et al. 1998) and assuming a generation time based on the age of first reproduction of approximately 10 years (Okoro 1983). The generation times were of 812 to 1,624 generations for $\mathrm{CAOB}$ and 1,730 to 3,472 for PION, and the likely decline in the size of populations could have occurred between 8,120 and 34,720 years ago. The time interval of population decline estimated coincides with periods of abundant rainfall and prolonged floods in the region (Leyden et al. 1998). The occurrence of $P$. caribaea var. hondurensis on raised platforms is consistent with the hypothesis that the water level and the duration of flooding in the marshes are directly correlated to Caribbean pine abundance (Dvorak et al. 2005).

\subsection{Conservation recommendations}

The information obtained in this study is of great use for delineating specific conservation strategies: the CAOB population needs to be formally delimited, and all anthropogenic activity (such as cutting trees, introduction of livestock, and burning) should be avoided. The implementation of these strategies ought to promote an increase in the currently low regeneration rate and provide an environment where seedlings can survive, grow, and increase the size of the natural reproduction. For the PION population, more explorations of the area are needed to confirm the census size that was reported in this work. We also recommend that this small population be listed in the Mexican red list (NOM-059-SEMARNAT-2001) and recognized as vulnerable. Since no regeneration was observed for this population, we recommend in situ conservation measures such as performing a general cleaning of the zone to generate gaps that allow for seed germination and establishment. For ex situ conservation of both populations, seeds should be collected from maturing cones (from June to August), with seed germination carried out offsite followed by reintroduction of seedlings to the area. These measures offer a highly desirable solution for the repopulation of these sites.

In summary, the use of molecular microsatellites markers enabled us to recognize intermediate levels of genetic variation, high levels of historical gene flow, and relatively high values of effective population sizes in Mexican populations of $P$. caribaea var. hondurensis. These results, together with the bottleneck tests, suggest that the Mexican populations come from the fragmentation of a large population that had a more continuous distribution in the past. Currently, populations are isolated, have extremely small census sizes, and exhibit evidence of loss of allelic variants and signs of inbreeding. Therefore, we recommend that a conservation strategy must be incorpo- rated into the management programs developed by the institutions responsible for safeguarding forest resources of Mexico.

Acknowledgements We thank D. Gernandt and A. Moreno for revision the manuscript. A. Larque for all logistical support that allowed the completion of the work. P. Sima, F. May, R. Ballesteros, and the residents of Communities of Caobas and Pioneros for their support during the fieldwork. A. Castillo and J. Cuello provided valuable technical assistance in the laboratory. We thank the several anonymous reviewers for giving valuable comments. This study was supported by SEP-CONACYT through the projects no. 44373 to PD and no. 46925 to DP.

\section{References}

Al-Rabab'ah MA, Williams CG (2004) An ancient bottleneck in the Lost Pines of central Texas. Mol Ecol 13:1075-1084

Beerli P (2006) Comparison of Bayesian and maximum-likelihood inference of population genetic parameters. Bioinformatics 22:341-345

Beerli P (2008) Migrate version 3.0, a maximum likelihood and Bayesian estimator of gene flow using the coalescent. Available at http://popgen.scs.edu/migrate.html

Boyce MS (1992) Pollination viability analysis. Ann Rev Ecol Syst 23:481-506

Boys J, Cherry M, Dayanandan S (2005) Microsatellite analysis reveals genetically distinct populations of red pine (Pinus resinosa, Pinaceae). Am J Bot 92:833-841

Cornuet JM, Luikart G (1996) Description and power analysis of two tests for detecting recent population bottlenecks from allele frequency data. Genetics 144:2001-2014

Dvorak WS, Hamrick JL, Gutiérrez EA (2005) The origin of Caribbean pine in the seasonal swamps of the Yucatán. Int $\mathrm{J}$ Plant Sci 166:985-994

Dvorak WS, Potter KM, Hipkins VD, Hodge GR (2009) Genetic diversity and gene exchange in Pinus oocarpa, a Mesoamerican pine with resistance to the pitch canker fungus (Fusarium circinatum). Int J Plant Sci 170:609-626

Echt CS, Marquardt PM, Hseih M, Zahorchak RR (1996) Characterization of microsatellite markers in eastern white pine. Genome 39:1102-1108

Elsik CG, Minihan VT, Hall SE, Scarpa AM, Williams CG (2000) Lowcopy microsatellite markers for Pinus taeda L. Genome 43:550-555

Excoffier L, Laval G, Schneider S (2005) Arlequin, ver 3.0: an integrated software package for population genetics data analysis. Evol Bioinf Online 1:47-50

Farjon A, Styles BT (1997) Pinus (Pinaceae). Flora Neotropical, monograph 75. New York Botanical Garden, New York, 246 pp

Furman BJ (1997) Phylogenetic informative markers as a diagnostic tool to identify species, hybrids and introgression in Central American and Mexican pines. Dissertation, Department of Genetics, North Carolina State University, Raleigh, 233 pp

Jaramillo-Correa JP, Beaulieu J, Ledig T, Bousquet J (2006) Decoupled mitochondrial and chloroplast DNA population structure reveals Holocene collapse and population isolation in a threatened Mexican-endemic conifer. Mol Ecol 15:2787-2800

Karhu A, Vogl C, Moran GF, Bell JC, Savolainen O (2005) Analysis of microsatellite variation in Pinus radiata reveals effects of genetic drift but no recent bottlenecks. J Evol Biol 19:167-175

Kimura M, Otha T (1978) Stepwise mutation model and distribution of allelic frequences in finite populations. Proc Natl Acad Sci USA 75:2868-2987 
Lande R (1993) Risk of population extinction from demographic and environmental stochasticity and random catastrophes. Am Nat 142:911-927

Ledig FT (1998) Genetic variation in Pinus. In: Richardson DM (ed) Ecology and biogeography of Pinus. Cambridge University Press, Cambridge, pp 251-280

Ledig FT, Conkle MT, Bermejo-Velazquez B, Eguiluz-Piedra T, Hodgskiss PD, Johnson DR, Dvorak WS (1999) Evidence for an extreme bottleneck in a rare Mexican pinyon: genetic diversity, disequilibrium, and the mating system in Pinus maximartinezii. Evolution 53:91-99

Leyden BW, Brenner M, Dahlin BH (1998) Cultural and climatic history of Cobá, a lowland Maya City in Quintana Roo. México Quat Res 49:11-122

Luikart G, Allendorf FW, Cornuet JM, Sherwin WB (1998) Distortion of alleles frequency distributions provides a test for recent population bottlenecks. J Hered 89:238-247

Macario MPA, Torres PS, Cabrera CE (1998) Estructura y composición de una comunidad de Pinus caribaea var. hondurensis (Sénecl) Barr. Et Golf., en el estado de Quintana Roo. México Caribb J Sci 34:50-57

Maruyama T, Fuerst PA (1985) Population bottlenecks and nonequilibrium models in population genetics II. Number of alleles in a small population that was formed by a recent bottleneck. Genetics 111:675-689
Okoro OO (1983) Influence of flowering habit of Pinus caribaea var. hondurensis Barr. et Golf on seed yield. Niger J For 13:36-42

Petit JR, Duminil J, Fineschi S, Hampe A, Salvini D, Vendramin GG (2005) Comparative organization of chloroplast, mitochondrial and nuclear diversity in plant populations. Mol Ecol 14:689-701

Piry S, Luikart G, Cornuet JM (1999) Bottleneck: a computer program for detecting recent reductions in the effective population size using allele frequency data. J Heredity 90:502-503

Shaffer ML (1981) Minimum population sizes for species conservation. Bioscience 31:131-134

Shepherd M, Cross M, Maguire TL, Dieters MJ, Williams CG, Henry RJ (2002) Transpecific microsatellites for hard pines. Theor Appl Genet 104:819-827

Smith DN, Devey ME (1994) Occurrence and inheritance of microsatellites in Pinus radiata. Genome 37:977-983

Van Oosterhout C, Hutchinson WF, Wills DPM, Shipley P (2004) MicroChecker: software for identifying and correcting genotyping errors in microsatellite data. Mol Ecol Notes 4:535-538

Vázquez-Lobo A (1996) Evolución de hongos endófitos del género Pinus L: implementación de técnicas moleculares y resultados preliminares. Dissertation, Universidad Nacional Autónoma de México, $66 \mathrm{pp}$

Wright S (1965) The interpretation of population structure by $F$-statistics with special regard to systems of mating. Evolution 19:395-420 